\title{
STRATEGI PENGEMBANGAN MODEL PEMBELAJARAN TRANSFORMATIF
}

\author{
Mohammad Naim \\ Program Studi Magister Manajemen Pendidikan Islam, Universitas Nurul Jadid
}

\begin{abstract}
Abstrak
Pembelajaran transformatif adalah proses pembelajaran yang 'mendekatkan' para peserta didik kepada kenyataan, menghadirkan pengetahuan yang kritis-reflektif, dengan memposisikan guru lebih sebagai fasilitator untuk mengarahkan dan mendorong proses tersebut. Dalam tulisan ini akan diulas pemaknaan dan lingkup pembelajaran transformatif yang sesuai dengan perkembangan diskusi kontemporer. Sehubungan dengan hal itu pula, beberapa pendekatan, strategi, dan metode yang relevan juga disajikan untuk menjadi pijakan dalam penyusunan model pembelajaran transformatif selanjutnya. Pada bagian akhir, strategi pengembangan model transformatif akan disintesis dengan mengidentifikasi determinan pada elemen-elemen yang terlibat.
\end{abstract}

Kata kunci: Pembelajaran transformatif, model pembelajaran, strategi pengembangan

\section{Pendahuluan}

Tujuan penyelenggaraan pendidikan secara substansial adalah untuk mempersiapkan peserta didik seutuhnya sehingga dapat memaknai hidup dan menjawab tantangan kehidupan yang dihadapinya. Oleh karena itu, sasaran pendidikan tidak saja pada pengembangan aspek kognitif, namun juga emosional-spiritual dan sosial. Daya nalar, kedewasaan emosi, empati sosial, dan spiritualitas merupakan sasaran yang harus terus dilibatkan pada proses transformasi peserta didik di dalam pendidikan. Dalam Undang-undang Nomor 2 tahun 2003 tentang Sistem Pendidikan Nasional ditegaskan bahwa tujuan pendidikan nasional adalah mengembangkan potensi peserta didik agar menjadi manusia yang beriman dan bertaqwa kepada Tuhan Yang Mahaesa, berkakhlak mulia, sehat, berilmu, cakap, kreatif, mandiri, dan menjadi warga negara yang demokratis dan bertanggung jawab.(Mundiri, 2017)

Sehubungan dengan hal tersebut, pembelajaran sebagai proses inti pendidikan selayaknya dijalankan dengan memposisikan peserta didik sebagai pemeran utama. Dengan demikian, aktivitas belajar dapat dijalani oleh mereka dengan penuh kesadaran, kerelaan, dan kebermaknaan dengan terlibat aktif di dalamnya (Hardika, 2012). Untuk mewujudkannya, aktivitas mengajar oleh seorang guru perlu dipahami lebih sebagai upaya fasilitasi pembelajaran (berupa pendampingan, pengarahan, pemberian motivasi, dan sebagainya) dari pada penyampaian informasi (Schwarz, 2002).

Selain itu, pembelajaran juga perlu dimaknai tidak sekedar transfer pengetahuan, tetapi lebih sebagai transfer belajar (transfer of learning), agar dapat mengantarkan peserta didik pada transformasi pola pikir dan pola tindak (Sullivan, 2001; Novak dan Gowin, 2004). Pemahaman terhadap materi ajar hanyalah pos awal dari tujuan berikutnya, yakni perubahan perspektif atau cara pandang terhadap hidup dan kehidupan, serta aksi nyata konsekuennya. Daya kritis dalam bingkai kesadaran personal dan sosial perlu dibangun atas basis potensi dan karkateristik setiap peserta didik. Inilah yang menjadi inti dari konsep pembelajaran transformatif (Mezirow, 1978; Freire, 1970; Daloz, 1986; Dirkx, 1998; Illeris, 2014).

\section{Teori Pembelajaran Transformatif (Pemaknaan dan Lingkup)}

Pembelajaran, secara praktikal, adalah kesatuan proses, cara, dan tindakan untuk membuat seseorang belajar. Pembelajaran lahir dari proses interaksi antara peserta didik, pendidik, dan sumber belajar pada suatu kondisi dan lingkungan belajar. Menurut Gagne 
(1985), untuk menghasilkan pembelajaran yang efektif, situasi eksternal perlu diperhitungkan dan dirancang sedemikian rupa untuk mengaktifkan, mendukung, dan mempertahankan proses-proses internal dalam belajar itu sendiri. Oleh karenanya, pembelajaran memiliki kedekatan dengan pengajaran yang dapat diartikan sebagai upaya sadar pendidik untuk membuat peserta didik belajar. Pengajaran lebih memberi kesan pekerjaan satu pihak, sedangkan pembelajaran mensyaratkan lebih pada interaksi antara pendidik dan peserta didik.

Di sisi lain, secara substansial, pembelajaran merupakan proses modifikasi atau perubahan kapasitas manusia ke tingkatan yang lebih tinggi (Gagne, 1985). Pembelajaran adalah upaya tranformasional, dimana sikap, perspektif, bahkan kepercayaan lama terusmenerus direkonstruksi dan diperbaharui berdasarkan peningkatan kapasitas pengetahuan dan pengalaman yang diperoleh. Berkaitan dengan hal tersebut, Jack Mezirow mengemukakan teori pembelajaran transformatif yang didefinisikan sebagai pembelajaran yang mampu mengubah kerangka acuan yang problematis menjadi lebih inklusif, toleran, reflektif, terbuka, dan secara emosional menerima pembaharuan (Mezirow, 2009).

Pandangan tentang pembelajaran transformatif awalnya digagas oleh Mezirow (1978) berdasarkan hasil kajian pada para wanita yang kembali bersekolah setelah berhenti sekian lama, bahwa pembelajaran mampu merubah perspektif mereka dalam memaknai kembali pengalaman dan kondisi kehidupannya. Dalam pandangan Mezirow (1996), pembelajaran dipahami sebagai proses pemaknaan kembali terhadap suatu pengalaman atau tindakan yang didasarkan pada pembaharuan atau revisi pemahaman yang sudah dimiliki sebelumnya. Pembelajaran transformatif, menurut Taylor (1998), merupakan suatu teori pembelajaran yang unik dalam hal kematangan, keabstrakan, idealitas, dan keselarasannya dengan perkembangan komunikasi alamiah manusia. ${ }^{1}$ Teori pembelajaran ini kemudian mendapat perhatian dan kajian yang luas, tidak saja dalam konteks pembelajaran formal, nonformal, dan informal, namun juga melibatkan berbagai subjek dan kelompok sosial yang berbeda (Taylor \& Cranton, 2012).(Mundiri \& Zahra, 2017)

Menurut Mezirow (1991), pembelajaran transformatif bermula ketika seseorang terlibat dalam aktivitas yang membuatnya berada pada "kebingungan arah" (disorienting dilemma), yaitu saat terjadi perbedaan antara kejadian yang dialami dengan keyakinan yang selama ini dianggap benar, sehingga menimbulkan semacam krisis personal. Kondisi inilah yang akan memicu perubahan pada kerangka acuan ${ }^{2}$ seseorang. Ketidakstabilan akibat krisis

\footnotetext{
${ }^{1}$ Mezirow menggunakan epistemologi teori tindakan komunikatif Habermas untuk memetakan perubahan struktur nilai (meaning structure) sebagai akibat proses pembelajaran. Perubahan pertama terjadi pada domain yang bersifat instrumental, dimana pembelajaran didasarkan pada penemuan-penemuan empiris-analitik (biasanya dalam bentuk penyelesaian masalah atau penarikan hubungan sebab-akibat). Singkatnya, domain instrumental menyangkut pemahaman tentang bagaimana sesuatu bisa terjadi (how things work). Sedangkan yang kedua bersifat komunikatif, dimana proses pembelajaran melibatkan pemahaman nilai, perasaan, sikap moral, dan semacamnya, dalam interaksi dengan orang lain (seperti dalam menyikapi soal keadilan, perdamaian , demokrasi). Pembelajaran transformatif dikatakan tercapai apabila refleksi kritis terjadi atas premis, asumsi, atau dugaan pada domain-domain pembelajaran tersebut. Lihat dalam J. Mezirow, Transfornative Dimensions of Adult Learning (San Francisco. Jossey-Bass. 1991)

${ }^{2}$ Kerangka acuan (frame of reference) inilah secara selektif akan membentuk dan membatasi persepsi, kognisi, perasaan serta karakter alamiah seseorang dengan mengarahkan niat, harapan, dan tujuannya. Dalam kerangka acuan ini pula, konteks makna dibangun atas pilihan-pilihan yang dibuat dan pengalaman-pengalaman sensorik yang dialami seseorang. Selanjutnya, pergeseran atau perubahan kerangka acuan yang dialami seseorang dapat terjadi dalam dua tataran makna/nilai (meaning), yaitu - yang dalam bahasa Mezirow disebut skema nilai (meaning schema) dan perspektif nilai (meaning perspective). Yang pertama tersusun dari penilaian, sikap, perasaan, dan keyakinan tertentu yang membentuk interpretasi personal seseorang. Sedangkan yang kedua adalah keseluruhan struktur asumsi kultural dan psikologis yang membentuk pola kognitif dan generalisasi yang dianut seseorang. Dengan kata lain, perspektif nilai sifatnya lebih fundamental karena merupakan akumulasi asumsi dimana pengalaman-pengalaman terdahulu berasimilasi dan pengalaman baru bertransformasi. Lihat dalam J. Mezirow, Learning to Think Like an Adult; Core Concepts of Transformation Theory, dalam J.

Mezirow \&Associates (Eds.), The Handbook of Transformative Learning: Theory, Research, and Practice (San Francisco Jossey-Bass, 2000), 35-77; dan F. Sayilan, "Jack Mezirow and Transformative Learning Theory" (Journal of Faculty of Educational Sciences, vol. 41, Ankara University, 2008), 299-316
} 
diri tersebut pada tahap selanjutnya akan mendorong orang tersebut untuk melakukan refleksi kritis (critical reflection) secara mandiri terhadap kerangka acuan yang membentuk konsepsi diri dan hidupnya, dan dialog reflektif (reflective discourse) dengan orang lain untuk mengkonfirmasi perubahan kerangka acuannya tersebut.

Pun demikian, deskripsi sebelumnya dimana kebingungan arah, refleksi kritis, dan diskursus reflektif terkesan sebagai fase elemen yang datang berurutan nyatanya tidaklah selalu demikian. Pembelajaran transformatif dapat terjadi dengan dipicu oleh satu atau kombinasi dari beberapa elemen tersebut. ${ }^{3}$ Pada bentuk yang lebih firmed, elemen-elemen ini lebih bergerak siklik dan terus menerus, sebagaimana model yang dikembangkan oleh Nerstrom (2014) untuk menjelaskan fase pembelajaran transformatif (Gambar 1).

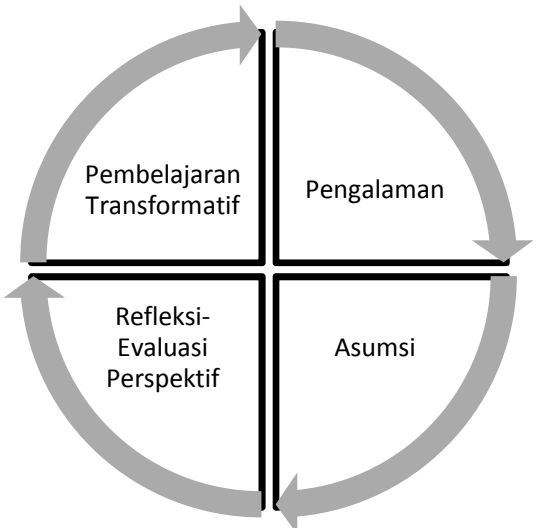

Gambar 1. Model fase pembelajaran transformatif Nerstrom Diadaptasi dari Nerstrom (2014)

Menurut pandangan Mezirow (2006), transformasi dalam pembelajaran terjadi pada perspektif nilai, kerangka acuan, dan pola pikir. Hal ini memang mengesankan aspek kognitif yang kentara dalam transformasi yang dimaksudkan oleh Mezirow, dan menjadi salah satu celah kritik dari berbagai pihak. Beberapa peneliti kemudian menekankan pula pentingnya menambahkan dimensi emosional dan sosial sebagai target transformasi (Cranton, 2005; Dirkx, 1998, 2006; Taylor, 2009). Bahkan lebih jauh, transformasi personal multidimensional tersebut dianggap perlu untuk diposisikan dalam bingkai kekuatan politik, ekonomi, dan sosial yang lebih luas. Berpijak pada berbagai pandangan di atas, dapat disimpulkan bahwa pembelajaran transformatif adalah konsep pembelajaran yang berorientasi pada terbentuknya transformasi perspektif individu sehingga menjadi lebih dewasa, bijaksana, serta kritis dalam berpikir dan bertindak, baik prosesnya bertumpu pada dimensi kognitif-rasional, afektifemosional, maupun komunikatif-sosial.(Baharun \& Mundiri, 2011)

\section{Model Pembelajaran: Kesatuan Konsep dan Praktik}

Model pembelajaran layaknya bingkai dari implementasi suatu pendekatan pembelajaran, berikut dengan metode serta teknik pembelajaran konsekuennya (Sumardi,

\footnotetext{
${ }^{3}$ Secara lebih rinci bahkan, Mezirow mengungkapkan sepuluh tahapan yang dapat terjadi dalam proses pembelajaran transformatif, yaitu: kebingungan arah; mengujian-diri, dengan perasaan takut, marah, bersalah, atau malu; refleksi kritis terhadap asumsi; menyadari bahwa ketidakpuasan, proses transformasi, dan perubahan sebagai sesuatu yang bisa dialami siapa saja, termasuk diri sendiri; mencari alternatif peran, hubungan, dan tindakan baru; merencanaan tindakan; akuisisi pengetahuan dan keterampilan baru; mencoba peran baru; membangun kompetensi dan kepercayaan diri; dan reintegrasi perspektif baru dalam kehidupan. Walaupun fasefase tersebut tersusun dengan baik, namun jalur untuk melaluinya dinilai rumit. Mezirow sendiri menjelaskan bahwa untuk mengalami pembelajaran transformatif, tidak semua fase perlu dialami, dan lagi urutan fase-fase tersebut mungkin terjadi pula secara acak. Lihat J. Mezirow, "Perspective Transformation", Adult Education Quarterly, Vol. 28, No. 2 (1978), 100-110; J. Mezirow, Transformative dimensions of adult learning (1991); J. Mezirow \& Associates, "Learning to think like an adult" (2000), 3-33; dan N. Nerstrom, "An Emerging Model for Transformative Learning" dalam Adult Education Research Conference Proceedings N. Nerstrom (dari http://newprairiepress.org/aerc/2014/papers/55, 2014), 325-330.
} 
2011). Dengan kata lain, model pembelajaran dapat dideskripsikan sebagai bentuk pembelajaran yang utuh: dari yang sifatnya pendekatan hingga detail teknik; dari apa yang dikonsepsikan hingga apa yang ditindak-manifestasikan. Ilustrasi tentang hubungan model, pendekatan, metode, dan teknik pembelajaran ${ }^{4}$ disajikan oleh Gambar 2.

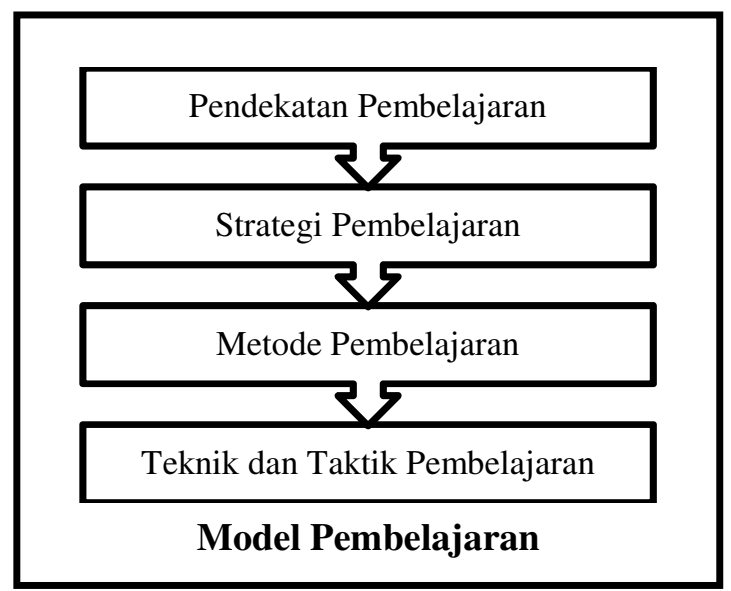

Gambar 2. Model pembelajaran sebagai bingkai utuh Diadaptasi dari Sumardi (2011)

\section{Ragam pendekatan pembelajaran transformatif}

Sebagaimana sekilas disinggung pada bagian sebelumnya bahwa pembelajaran transformatif membawa ragam pandangan terkait dimensi pembelajaran yang bertransformasi. Hal ini berkaitan erat dengan latar pendekatan yang digunakan untuk mengkonsepsikan teori pembelajaran transformatif. Ditinjau dari pendekatannya, menurut Dirkx (1998) dan Hoggan (2015), pembelajaran transformatif dapat dikelompokkan menjadi empat, yaitu: (1) learning for consciousness-raising, (2) learning for critical reflection, (3) learning for development, dan (4) learning for individuation.

Pembelajaran (atau pendidikan) transformatif sebagai peningkatan kesadaran (consciousness-raising) dikemukakan oleh Paulo Freire (1970). ${ }^{5}$ Kesadaran kritis yang dimaksudkan Freire merujuk pada proses dimana pembelajar meningkatkan kemampuan analisis, menghadapi persoalan, dan melakukan tindakan dalam konteks sosial, politik, kultural, dan ekonomi yang mempengaruhi dan membentuk kehidupannya. Kepekaan ini diperlukan untuk memahami strktur sosial yang berlaku di lingkungannya sehingga bisa terbebas dari resiko dan tindak penindasan dan kesewenang-wenangan.

Selanjutnya, pembelajaran transformatif yang diorientasikan pada refleksi kritis (critical reflection) digagas dan dikembangkan oleh Jack Mezirow. Dalam pandangannya,

\footnotetext{
${ }^{4}$ Sekedar penyegaran definisi, pendekatan pembelajaran merujuk pada pandangan atau konsepsi general yang dijadikan titik tolak dalam memandang pembelajaran - sebagai pijakan teoritis yang menginspirasi dan melatari cara pandang. Strategi pembelajaran mengacu pada bentuk tindakan pembelajaran guru dan murid untuk ketercapaian tujuan pembelajaran secara efektif dan efisien. Metode pembelajaran, pada tingkat lebih praksis, berupa kegiatan nyata yang disusun berdasarkan strategi pembelajaran yang telah dipilih. Jika strategi dianggap sebagai "a plan of operation", maka metode adalah "a way in implementing the plan". Dari metode pembelajaran, teknik dan taktik pembelajaran kemudian disusun dengan mempertimbangkan faktor teknis di lapangan.

${ }^{5}$ Gagasan Freire ini berakar pada kegiatan sosialnya terkait pendidikan literasi bagi kelompok pekerja miskin di Brazil. Melalui kegiatan pembelajaran yang memposisikan peserta didik sebagai partisipan aktif (emansipatoris), Freire berhasil menyadarkan mereka bahwa selama ini mereka digaji tidak layak sebagai pekerja. Pembelajaran yang dilakukan oleh Freire mengedepankan diskusi, posing-problem, dan refleksi terhadap persoalan kehidupan yang relevan. Ini sebagai bentuk alternatif pembelajaran yang marak dipaktekkan dengan menempatkan peserta didik hanya sebagai pendengar dan penerima informasi, tanpa didorong reflektif ataupun dilibatkan secara aktif dalam pembelajaran. Pendekatan demikian kemudian dikenal dengan istilah emancipatory approach. Lihat P. Freire, Pedagogy of The Oppressed; $20^{\text {th }}$ Anniversary Revised Edition (New York, Seabury Press, 2000), 17-53
} 
peserta didik perlu dikondisikan untuk membangun refleksi kritis atas asumsi awal yang telah dimiliki dengan cara mengkronfrontasikannya dengan asumsi-asumsi lain yang berbeda secara substansial atau dengan kenyataan yang "menggoyahkan" asumsi awalnya tersebut. Melalui proses kritis-reflektif tersebut, perspektif baru dapat terbentuk dan kemudian menjadi dasar tindakan peserta didik. Perubahan pada sisi perspektif dengan pendekatan rasionalkognitif inilah yang menjadi penekanan dalam pembelajaran transformatif Mezirow.

Pada sisi lain, perspektif perkembangan peserta didik (developmental perspective) juga digunakan sebagai basis dalam memahami pembelajaran transformatif, seperti yang diartikulasikan pertama kali oleh Larry Daloz (1986). Ia memandang bahwa kebutuhan untuk menemukan dan membangun kebermaknaan hidup (meaning) sebagai faktor kunci yang mendorong orang dewasa untuk terlibat dalam sebuah pembelajaran formal. Dan ini, masih menurut Daloz, berkaitan erat dengan perkembangan kehidupan kita sendiri. Tingkat "kematangan" dan kondisi lingkungan yang berubah akan menuntut seseorang bergerak dari fase perkembangan saat itu ke fase berikutnya - melalui pelibatkan diri dalam proses pembelajaran. Dari sini, sangatlah jelas perspektif 'perkembangan dan perubahan' (growth and transformation) yang mendasari pandangan Daloz dalam pembelajaran transformatif walaupun masih dipengaruhi oleh konteks sosio-kultural yang melatarbelakanginya (Dirkx, 1998).

Aliran pendekatan yang keempat tentang pembelajaran transformatif pertama kali direpresentasikan oleh Robert Boyd (1991; Boyd \& Myers, 1988). Walaupun pandangannya memiliki irisan dengan Daloz, Mezirow, dan Freire, Boyd meletakkan perkembangan kesadaran, perubahan, dan perkembangan pada makna yang berbeda. Perhatian Boyd lebih pada dimensi ekspresif atau emosional-spiritual dan mengintegrasikannya secara menyeluruh dan holistik dalam kehidupan sehari-hari. Pembelajaran transformatif, lanjut Boyd, melibatkan proses identifikasi 'simbol-simbol' dan dialog intrapersonal untuk memahaminya. Dialog ini merupakan bagian dari proses lebih luas yang - dalam istilah Carl Jung - disebut individuasi, yaitu proses untuk 'menyelami' dan memahami diri sendiri lebih jauh, sehingga dapat terhindar dari obsesi, keserakahan, dan bagian gelap lain yang mungkin muncul dari 'ketidaksadaran' (Dirkx, 1998).

Selain pandangan-pandangan di atas, terdapat pula pandangan lain yang berusaha mengakomodasi semua dimensi transformasi tersebut, salah satunya adalah Knud Illeris (2014). Ia mengajukan pandangan bahwa target pembelajaran transformatif dapat tercakup dalam terma 'identitas'. Identitas yang dimaksud yaitu kombinasi dari pengalaman personal yang khas dalam situasi apapun dan bagaimana seseorang 'menampilkan' dirinya terhadap lingkungannya. Jadi, identitas merujuk pada kompleksitas jati diri personal dan sosial seseorang.

\section{Strategi Pengembangan Model Pembelajaran Transformatif: Identifikasi Determinan}

Hal paling mendasar untuk dijadikan titik tolak dalam desain dan pengembangan model pembelajaran transformatif adalah mengidentifikasi proses-proses kunci dan determinannya. Berkenaan dengan hal tersebut, Mezirow (1995) sendiri menekankan bahwa proses yang paling signifikan dalam pembelajaran transformatif terjadi pada domain komunikatif, yakni bermula dari identifikasi masalah, nilai-nilai, atau perspektif awal, pengujian asumsi, dialog dengan diskursus kritis, hingga pada pengambilan kesimpulan berdasarkan hasil diskursus. Pun demikian, masih menurut Mezirow (1997) terdapat empat rangkaian proses yang disyaratkan agar transformasi terwujud, yaitu (1) mengelaborasi atau memperbaiki skema makna/nilai, (2) mempelajari skema makna baru, (3) merubah skema makna, dan (4) merubah perspektif makna.

Pada tataran selanjutnya, McGonigal (2005) mengemukakan lima langkah implementatif agar transformasi peserta didik dapat terwujud, yaitu:

1. Activating event, yaitu peristiwa atau kejadian yang membuat peserta didik menyadari keterbatasan pengetahuan/pemahaman yang dimilikinya; 
2. Ketersediaan ruang atau kesempatan untuk mengidentifikasi dan mengartikulasikan asumsi-asumsi yang mendasari pengetahuan awalnya tersebut;

3. Refleksi kritis;

4. Diskursus kritis, dengan dialog dan diskusi;

5. Kesempatan untuk menguji dan mengaplikasikan perspektif baru.

Tabel 1. Strategi pengajaran untuk pembelajaran transformatif ${ }^{6}$

\begin{tabular}{|c|c|}
\hline Proses Kunci & Strategi Pengajaran \\
\hline Activating event & $\begin{array}{l}\text { Guru (pendidik) secara sistematis dan sengaja: } \\
\text { - Mengkaji latar belakang peserta didik } \\
\text { - Menyajikan sudut pandang yang berbeda dalam } \\
\text { - } \text { pembelajaran } \\
\text { - Mengkondisikan disorienting dilemma pada peserta didik } \\
\end{array}$ \\
\hline Identifikasi asumsi awal & $\begin{array}{l}\text { Guru mengajak, atau mengkondisikan peserta didik untuk: } \\
\text { - Mengkritisi persoalan } \\
\text { - Membuat prediksi tentang suatu kejadian, eksperimen, } \\
\text { atau prosedur kerja/penyelesaian } \\
\text { - Menjelaskan gagasan atau strategi penyelesaian masalah } \\
\text { - Mengevaluasi gagasan-gagasan lain untuk mempertegas } \\
\quad \text { kerangka gagasannya sendiri }\end{array}$ \\
\hline Mendorong refleksi kritis & $\begin{array}{l}\text { Dengan memberikan penugasan mandiri, guru meminta } \\
\text { peserta didik untuk: } \\
\text { - Membuat jurnal yang memuat pertanyaan, pengamatan, } \\
\text { dan percobaan } \\
\text { - Memberikan respon terhadap peristiwa atau bahan bacaan } \\
\text { tertentu } \\
\text { - Membuat timeline 'riwayat perspektif' }\end{array}$ \\
\hline $\begin{array}{l}\text { Mendorong diskursus } \\
\text { kritis }\end{array}$ & $\begin{array}{l}\text { Melalui tanya-jawab atau diskusi, guru mengkondisikan } \\
\text { peserta didik untuk: } \\
\text { - Menganalisis pendekatan yang dipakai pada suatu konsep, } \\
\text { paradigma, atau strategi baru, dan membandingkannya } \\
\text { dengan asumsi awal } \\
\text { - Meluangkan waktu tambahan untuk diskusi } \\
\text { - Melaporkan atau menindaklanjuti diskusi di luar kelas } \\
\text { - Membentuk kelompok studi atau projek bersama }\end{array}$ \\
\hline $\begin{array}{l}\text { Pemberian ruang untuk uji } \\
\text { paradigma/perspektif baru }\end{array}$ & $\begin{array}{l}\text { Guru secara sistematis dan sengaja: } \\
\text { - Melakukan pengayaan kasus dan meminta peserta didik } \\
\text { menyelesaikannya dengan perspektif baru yang telah } \\
\text { dimiliki, dan/atau dengan berbagai perspektif serta } \\
\text { keluaran yang dihasilkan oleh masing-masing } \\
\text { - Mengajak peserta didik untuk melakukan latihan bersama: } \\
\text { simulasi, role-playing, debat, dll. untuk menguji } \\
\text { kedalaman perspektif } \\
\text { - Mengajak peserta didik untuk melakukan observasi dan } \\
\text { interpretasi peristiwa, percobaan, atau bacaan tertentu, } \\
\text { dengan menerapkan perspektif baru yang sudah diperoleh }\end{array}$ \\
\hline
\end{tabular}

\footnotetext{
${ }^{6}$ Dirangkum dan disarikan dari K. McGonigal, Teaching for Transformation: From Learning Theory to Teaching Strategies (Speaking of Teaching (Newsletter), The Center for Teaching and Learning - Stanford University, 2005), Vol. 14(2).
} 
Lebih lanjut, dari proses kunci di atas, kemudian diturunkan beberapa strategi yang dapat diimplementasi oleh guru (pendidik) dalam proses pengajaran (Tabel 1).

Terkait pedagogi pembelajaran, Taylor (1998) juga mengungkapkan beberapa praktik yang perlu diberikan penekanan lebih untuk menumbuhkan pembelajaran transformatif. Tabel 2 menyajikan rangkuman aspek kunci atau determinan dalam pedagogi pembelajaran transformatif.

Tabel 2. Determinan dalam pedagogi pembelajaran transformatif ${ }^{7}$

\begin{tabular}{ll}
\hline \multicolumn{1}{c}{ Basis Pembelajaran } & \multicolumn{1}{c}{ Determinan } \\
\hline Pengkondisian Kelompok & - Keterbukaan dan standing terhadap latar belakang \\
& kultural \\
& - Merangkul disonansi dan konflik \\
& - Ruang dan kesempatan mengekspresikan gagasan baru \\
\hline Pengalaman & - Akomodasi keragaman gaya pembelajaran \\
& - Kedekatan dengan kelompok berbagi pengalaman \\
& - Motivasi diri \\
& - Sensibilitas estetik \\
& - Refleksi kritis \\
& - Pembelajaran afektif: keterlibatan emosi \\
\hline Waktu & Alokasi dan keseimbangan antara tuntutan kurikulum, \\
& murid, dan institusi \\
\hline Kecenderungan terhadap & Determinasi etis guru \\
perubahan & \\
\hline Pembelajaran afektif & - Prasyarat awal refleksi-kritis \\
& - Sisi provokatif dan evokatif \\
& - Kepercayaan dan penghargaan diri \\
& - Kedalaman refleksi-kritis \\
\hline Peran guru dan murid & Pemahaman sebagai never-ending transformative learner \\
\hline
\end{tabular}

\section{Prosedur pengembangan model}

Setelah mengetahui determinan secara detail, sebuah model pembelajaran transformatif kemudian dapat disusun. Pengembangan model pembelajaran, termasuk juga pembelajaran transformatif, dapat dilakukan salah satunya dengan menerapkan desain instruksional berbasis ADDIE (Analysis, Design, Development, Implementation, and Evaluation) yang dikembangkan oleh Dick \& Carey (1996). Langkah implementasi model ADDIE secara singkat disajikan dalam Tabel 3.

Tabel 3. Langkah implementasi ADDIE untuk pengembangan model pembelajaran

\begin{tabular}{ll}
\hline Tahap Pengembangan & \multicolumn{1}{c}{ Aktivitas } \\
\hline Analisis & $\begin{array}{l}\text { Identifikasi masalah pembelajaran, menetapkan tujuan dan sasaran } \\
\text { pembelajaran, karakteristik dan latar belakang peserta didik, } \\
\text { pengetahuan awal, dan sebagainya; juga mempertimbangkan }\end{array}$ \\
& $\begin{array}{l}\text { lingkungan belajar, potensi hambatan, opsi penyampaian, dan } \\
\text { timeline }\end{array}$ \\
\hline Desain & $\begin{array}{l}\text { Merancang proses sistematis dari tujuan pembelajaran yang telah } \\
\text { ditetapkan, termasuk menetapkan pemilihan strategi dan metode } \\
\text { pembelajaran, alur proses, isi, dan media yang dibutuhkan. }\end{array}$ \\
\hline
\end{tabular}

\footnotetext{
${ }^{7}$ Dirangkum dan disarikan dari E. W. Taylor, The Theory and Practice of Transformative Learning: A Critical Review (ERIC Clearinghouse on Adult, Career, and Vocational Education, The Ohio State University, 1998), 47-60
} 


\begin{tabular}{ll}
\hline Tahap Pengembangan & \multicolumn{1}{c}{ Aktivitas } \\
\hline Pengembangan & $\begin{array}{l}\text { Menyiapkan perangkat yang diperlukan berdasarkan desain yang } \\
\text { dibuat, mencakup penyiapan materi, bahan, alat, media } \\
\text { pembelajaran, serta instrumen pengukuran kinerja }\end{array}$ \\
\hline Implementasi & $\begin{array}{l}\text { Menerapkan hasil yang didapatkan dari tahap desain dan } \\
\text { pengembangan }\end{array}$ \\
\hline Evaluasi & $\begin{array}{l}\text { Mengkaji ulang dampak pembelajaran yang dihasilkan, mengukur } \\
\text { ketercapaian tujuan pembelajaran, revisi model pembelajaran }\end{array}$ \\
\hline
\end{tabular}

Tahapan implementasi ADDIE di atas merupakan proses yang iteratif. Artinya, hasil evaluasi dan perbaikan dari setiap ujung tahap/fase dapat dijadikan basis untuk meninjau ulang tahap sebelumnya. Selain itu, produk yang dihasilkan dalam sebuah fase merupakan input produk fase berikutnya. Dengan demikian, perbaikan terus-menerus untuk memperbaiki model-model yang sudah terbentuk dapat secara kontinu dilakukan dengan mengikuti alur yang sama.

\section{Kesimpulan}

Tujuan pembelajaran transformatif sejatinya perlu dipahami untuk mengembalikan tugas pendidikan sebagaimana mulanya, yaitu membentuk manusia seutuhnya. Tidak saja untuk mengembangkan kapasitas kritis-reflektif personal peserta didik dalam kognitif, emosional, dan spiritualnya, namun juga melekatkannya pada bingkai sosial dan lingkungan dimana dia berada. Pun dengan tujuan tersebut, upaya perwujudannya perlu melalui identifikasi aspek kunci dan penyusunan model implementatif yang sistematis dan sesuai dengan karakteristik pembelajaran transformatif itu sendiri. Model pembelajaran yang terbentuk nantinya harus benar-benar berupa representasi praktikal dari pembelajaran transformatif, dengan menyesuaikan pemilihan strategi dan metode yang mendukung. Proses kunci pembelajaran transformatif (disorienting dilemma, refleksi kritis, diskursus reflektif, dan transformasi diri) perlu selalu ditempatkan sebagai perhatian utama dalam penyusunan model implementatif tersebut.

\section{DAFTAR RUJUKAN}

Boyd, R. D. 1991. Personal Transformation in Small Group: A Jun-gian Perspective. London: Routledge.

Boyd, R. D. dan G. J. Myers. 1988. Transformative Education. International Journal of Lifelong Education, Vol. 7(4), 261-284.

Cranton, P. 2005. Understanding and Promoting Transformative Learning. San Francisco: Jossey-Bass.

Daloz, L. 1986. Effective Teaching and Mentoring: Realizing the Transformational Power of Adult Learning Experiences. San Francisco: Jossey-Bass.

Dick, W. dan L. Carey. 1996. The Systematic Design of Instruction (4 ${ }^{\text {th }}$ Ed.). New York: Harper Collins College Publishers.

Dirkx, J.M. 1998. Transformative Learning Theory in the Practice of Adult Education: An Overview. PAACE Journal of Lifelong Learning, Vol. 7

Dirkx, J. M. 2006. Engaging Emotions in Adult Learning: A Jungian Perspective on Emotion and Transformative Learning. Dalam E. Taylor (Ed.), Teaching for Change: New Directions in Adult and Continuing Education, 109, 15-26.

Freire, P. 1970. Pedagogy of The Oppressed. New York: Seabury Press.

Freire, P. 2000. Pedagogy of The Oppressed, $20^{\text {th }}$ Anniversary Revised Edition. New York: Seabury Press.

Gagne, R. M. 1985. Conditions of Learning ( $4^{\text {td }}$ ed.). New York: Holt, Rinehart, and Wilson. 
Hardika. 2012. Pembelajaran Transformatif Berbasis Learning How To Learn: Teori, Model, dan Implementasinya dalam Pembelajaran. Malang: UMM Press.

Hoggan, C.D. Transformative Learning as Metatheory: Definition, Criteria, and Typology. Adult Education Quarterly, 1-19.

Illeris, K. 2014. Transformative Learning and Identity. Journal of Transformative Education, Vol. 12(2), 148-163.

McGonigal, K. 2005. Teaching for Transformation: From Learning Theory to Teaching Strategies. Speaking of Teaching (Newsletter), The Center for Teaching and Learning, Stanford University, Vol. 14(2).

Mezirow, J. 2009. Transformative Learning Theory. Dalam J. Mezirow, E. W. Taylor, \& Associates (Eds.), Lifelong Learning: Concepts and Contexts. London: Routledge

Mezirow, J. 1978. Perspective Transformation. Adult Education Quarterly, Vol. 28(2).

Mezirow, J. 2006. An Overview over Transformative Learning. Dalam P. Sutherland \& J. Crowther (Eds.), Lifelong learning: Concepts and Contexts. London: Routledge.

Mezirrow, J. 1996. Contemporary Paradigms of Learning. Adult Education Quarterly, Vol. 46(3), 158-172.

Mezirow. 1991. Transfornative Dimensions of Adult Learning. San Francisco: Jossey-Bass

Mezirow, J. 2000. Learning to Thing Like an Adult; Core Concepts of Transformation Theory. Dalam J. Mezirow \& Associates (Eds.), The Handbook of Transformative Learning: Theory, Research, and Practice. San Francisco: Jossey-Bass

Nerstrom, N. 2014. An Emerging Model for Transformative Learning. Adult Education Research Conference Proceedings. http://newprairiepress.org/aerc/2014/papers/55. Diakses pada 26 Februari 2018.

Novak, J. D. dan B. D. Gowin. 2004. Learning How To Learn. London: Cambridge University Press.

Sayilan, F. 2008. Jack Mezirow and Transformative Learning Theory. Journal of Faculty of Educational Sciences, Ankara University, Vol. 41, 299-316.

Schwarz, R. 2002. The Skilled Facilitator: A Comprehensive Resourse for Consultants, Facilitators, Managers, and Coaches. San Francisco: Jossey-Bass.

Sumardi, K. 2011. Pengembangan Model-model Pembelajaran. http://kaminsumardi.staf.upi.edu/files/2011/10/Makalah-Model-Pembelajaran.pdf. Diakses pada 24 Februari 2018.

Sullivan, E. O'. 2001. Transformative Learning: Educational Vission for the $21^{\text {st }}$ Century. Toronto: University of Toronto Press.

Taylor, E. W. 1998. The Theory and Practice of Transformative Learning: A Critical Review. Ohio: ERIC Clearinghouse on Adult, Career, and Vocational Education, The Ohio State University.

Taylor, E. W. 2009. Fostering Transformative Learning. Dalam J. Mezirow, E. W. Taylor, \& Associates (Eds.), Transformative Learning in Practice: Insights from Community, Workplace and Higher Education. San Francisco: Jossey-Bass.

Taylor, E. W. dan P. Cranton (Eds.). 2012. The Handbook of Transformative Learning: Theory, Reasearch, and Practice. San Francisco: Jossey-Bass.

Baharun, H., \& Mundiri, A. (2011). Metodologi Studi Islam: Percikan Pemikiran Tokoh Dalam Membumikan Agama. Ar-Ruzz Media (1st ed.). Yogyakarta: Ar-Ruzz Media.

Mundiri, A. (2017). Organizational Culture Base On Total Quality Management In Islamic Educational Institution. ADRI International Journal Of Islamic Studies and Social Sciences, 1(1), 1-11.

Mundiri, A., \& Zahra, I. (2017). IMPLEMENTASI METODE STIFIn DALAM MENINGKATKAN KEMAMPUAN MENGHAFAL AL-QUR'AN DI RUMAH QUR'AN STIFIn PAITON PROBOLINGGO. Journal of Islamic Education Studies), 5(2), 201-223. https://doi.org/10.15642/jpai.2017.5.2.201-223 
